\title{
Dehydrogenation of Light Alkanes over Zeolites
}

\author{
Thomas F. N arbeshuber, A xel Brait, Kulathuyier Seshan, and Johannes A . Lercher \\ Christian D oppler L aboratory for H eterogeneous Catalysis, D epartment of Chemical Technology, University of Twente, \\ P.O. B ox 217, 7500 A E E nschede, The N etherlands
}

R eceived M arch 17, 1997; revised A ugust 4, 1997; accepted A ugust 5, 1997

The conversion of light paraffins to olefins and the secondary reactions of the unsaturated compounds were investigated on $\mathrm{H}-\mathrm{ZSM} 5$ and $\mathrm{H}-\mathrm{Y}$ zeolites between 733 and $823 \mathrm{~K}$. Steady stateand transient response-isotope tracing studies revealed that two mechanisms of dehydrogenation are operative. The main pathway is represented by monomolecular, protolytic dehydrogenation. This reaction contributes most to steady state olefin production. Additionally, at the initial stages of the reaction, extra framework aluminum moieties are speculated to participate in high dehydrogenation activity. This pathway is blocked at later stages of the reaction by product (hydrogen) inhibition. The intrinsic rates of protolytic dehydrogenation and olefin desorption range in the same order of magnitude. At high protolytic dehydrogenation rates, olefin desorption represents the rate determining step. Depending on the process conditions, olefins undergo secondary cracking, oligomerization, or isomerization. The latter proceeds via intramolecular rearrangement, possibly via a cyclopropylcarbenium ion at high temperatures and low conversions. At reaction conditions where bimolecular cracking prevails, isomerization is concluded to occur via secondary cracking of di- or oligomers.

(c) 1997 A cademic Press

\section{INTRODUCTION}

M onomolecular catalytic cracking was shown to proceed via protolysis of the substrate and subsequent decomposition of the so formed carbonium ion (1-3). Similarly, monomolecular dehydrogenation can be visualized to proceed via protolysis followed by the release of hydrogen and the formation of a carbenium ion/alkoxy group $(4,5)$. We discussed the principal scheme of protolytic dehydrogenation recently $(1,2,5)$, using the conversion of n-butane as an example. However, the mechanism(s) of alkane dehydrogenation and the nature of the catalytically active sites are still controversial (3-15). B renner and Emmett (7) postulated acidic dehydrogenation sites and excluded an earlier opinion about metal impurities to cause dehydrogenation. M cVicker (8) suggested that strong electron deficient sites are present that effect a radical decomposition of the substrate, a view accepted by Bizreh and $G$ ates (11). M arczewski (12), and B eyer (15) held L ewis acid sites responsible.

Carbenium ions, once formed via dehydrogenation on zeolites, may (i) desorb as olefins from the catalyst, (ii) un- dergo double-bond-, cis/trans-, and skeletal isomerization, (iii) di- and/or oligomerize, or crack further into smaller olefins and carbenium ions. The extent to which these processes occur depends on the acidity of the catalyst and on the shape and concentration of the olefins. Several groups including ourselves showed that di- and oligomerization requires high concentrations of the olefins $(2,16-18)$. High reactant pressures, high conversions, and low temperatures favor these processes. A t low olefin concentrations, desorption is preferred over the bimolecular reaction.

The isomerization of olefins was studied in a number of publications during the past (18-35). D ouble-bond and cis-trans isomerization, as well as the skeletal rearrangement of these substances, were in the focus of interest (e.g., $(18,19,33))$. D ue to the increasing demand for i-butene as a reactant in the synthesis of methyl-tert-butyl-ether (M TBE ) (32-35) isomerization of n-butene to i-butene was recently discussed in several articles. Two reaction pathways appear to describe the observations of kinetic experiments, i.e., (i) a monomolecular rearrangement and (ii) an isomerization via a di- or oligomer species, which selectively crack. It is currently believed that carbenium ions with more than four carbon atoms might isomerize via the formation of a cyclopropyl intermediate (31). The current argument against the monomolecular rearrangement of the butylcarbenium ion is based on the fact that, assuming a methyl-cyclopropylcarbenium ion as intermediate, a primary carbenium ion has to be formed to yield i-butene. Houzvicka and Ponec (32) concluded that isomerization occurs via a monomolecular pathway on B rønsted acid sites.

In the present communication we focus on the high temperature (733-823 K) dehydrogenation of light paraffins and subsequent reactions of the olefins, mainly isomerization. Two mechanisms of dehydrogenation and isomerization will be discussed with respect to the results obtained from steady state- as well as ${ }^{13} \mathrm{C}$ - and D -tracing studies. The rate determining steps of both routes will be evaluated.

\section{EXPERIMENTAL}

The catalytic conversion of light hydrocarbons ( propane, $\mathrm{n}$-butane, i-butane, $\mathrm{n}$-pentane, i-pentane, and n-hexane) was investigated on $\mathrm{H}-\mathrm{ZSM} 5$ and $\mathrm{H}-\mathrm{Y}$ zeolites. The 
TABLE 1

Physicochemical Characterization (Values Taken from R ef. (36))

\begin{tabular}{|c|c|c|c|}
\hline & $H Y-P$ & HY-M & H-ZSM 5 \\
\hline$\left.A\right|_{\text {total }}(E D A X)[\mathrm{mol} / \mathrm{g}]$ & $2.7 \times 10^{-3}$ & $3.7 \times 10^{-3}$ & $4.4 \times 10^{-4}$ \\
\hline $\mathrm{A}$ Itetrahedral $\left({ }^{29} \mathrm{Si}-\mathrm{N} \mathrm{M} \mathrm{R}\right)[\mathrm{mol} / \mathrm{g}]$ & $2.0 \times 10^{-3}$ & $2.1 \times 10^{-3}$ & $4.1 \times 10^{-4}$ \\
\hline $\begin{array}{l}\text { A cid sites } \mathrm{NH}_{3} \text { adsorption } \\
\quad=\text { B rønsted acid sites [mol/g] }\end{array}$ & $6.6 \times 10^{-4}$ & $1.2 \times 10^{-3}$ & $4.2 \times 10^{-4}$ \\
\hline $\begin{array}{l}\text { A cid sites pyridine adsorption } \\
\text { = B rønsted acid sites [mol/g] }\end{array}$ & $6.0 \times 10^{-4}$ & - & $4.2 \times 10^{-4}$ \\
\hline$\Delta \mathrm{H}_{\mathrm{ads}}-\mathrm{NH}_{3}[\mathrm{~kJ} / \mathrm{mol}]$ & 140 & 142 & 147 \\
\hline $\begin{array}{l}\text { EFA L }\left(I R v_{O H}=3617 \mathrm{~cm}^{-1}\right) \\
\text { [arbitrary units] }\end{array}$ & 1.04 & 0.49 & - \\
\hline
\end{tabular}

physicochemical characteristics of the samples were taken from R ef. (36). They are compiled in Table 1. H -ZSM 5 had a Si/A I ratio of 35 and a particle size of approximately $1 \mu \mathrm{m}$. Infrared spectroscopy showed two characteristic hydroxyl adsorption bands at 3610 and $3745 \mathrm{~cm}^{-1}$. They were assigned to B rønsted acid sites and terminal hydroxyl groups, respectively. L ewis acid sites were not detected. I ron impurities were smaller than 500 ppm in the $\mathrm{H}$-ZSM 5 sample.

HY-P(arent) was a dealuminated faujasite, obtained from $D$ egussa. This sample contained large amounts of extra framework aluminum. HY-M (odified) was obtained by leaching $\mathrm{H} Y-\mathrm{P}$ with $0.1 \mathrm{~N}$ ammoniumhydroxide solution to remove large fractions of the extralattice aluminum species.

Steady state and transient response experiments were carried out in a plug flow reactor using a quartz glass tube with an inner diameter of $4 \mathrm{~mm}$ (for a detailed description see $\mathrm{R}$ ef. (2)). The reactions were investigated between 733 and $823 \mathrm{~K}$. Propane or $\mathrm{n}$-butane were used as 10 or $2 \%$ mixture in $\mathrm{He} 5.0$, respectively. Pentane and hexane were added to the carrier gas via a syringe pump. Partial pressures of the reactants ranged from $10 \mathrm{~Pa}$ to $10 \mathrm{kPa}$. The catalyst weight was varied from 0.002 to $0.05 \mathrm{~g}$. Flow rates were adjusted from 10 to $100 \mathrm{ml} / \mathrm{min}$ to keep the conversion below $5 \%$, so that the reactor operated under differential conditions.

\section{RESULTS}

R ates of R eaction, E nergies of A ctivation, and Reaction O rders

The conversion of light hydrocarbons was carried out between 733 and $823 \mathrm{~K}$ on $\mathrm{H}-\mathrm{Y}$ and $\mathrm{H}-\mathrm{ZSM} 5$ zeolites. A detailed interpretation of the steady state results was al ready given earlier $(1,2,37)$ and will only be summarized here.

The rates of cracking and dehydrogenation at $773 \mathrm{~K}$ are compiled in Table 2. The corresponding energies of activation are compiled in Table 3. The observed product distributions could be explained by monomolecular cracking and
TABLE 2

\section{Rates of $C$ racking and D ehydrogenation at $773 \mathrm{~K}$ $[\mathrm{mol} / \mathrm{g} \mathrm{s} \mathrm{mbar}] \times 10^{9}$}

\begin{tabular}{|c|c|c|c|c|}
\hline \multirow[b]{2}{*}{$R$ ates } & \multicolumn{2}{|r|}{$H Y-M$} & \multicolumn{2}{|r|}{ H-ZSM 5} \\
\hline & Cracking & D ehydrogenation & Cracking & D ehydrogenation \\
\hline Propane & 0,54 & 0,53 & 1,1 & 0,6 \\
\hline n-B utane & 4,20 & 2,90 & 7,3 & 2,8 \\
\hline n-Pentane & 41,0 & 30,8 & 37,5 & 12,3 \\
\hline n-H exane & n.d. & n.d. & 126 & 32 \\
\hline
\end{tabular}

monomolecular dehydrogenation. It was clearly observed that the apparent energies of activation for dehydrogenation increased with increasing molecular weight of the feed on $\mathrm{H} Y-M$ and $\mathrm{H}-\mathrm{ZSM} 5$, while those for cracking decreased. The addition of the heats of adsorption of the corresponding hydrocarbon to the apparent energy of activation for cracking yielded a constant true energy of activation indicating that the energy which is required to be overcome to cleave a carbon-carbon bond does not depend on the chain length of the hydrocarbon. In contrast, the true energy of activation for dehydrogenation increased, because both, heats of adsorption and apparent energies of activation, increased with increasing carbon chain length. This suggests different mechanisms or different rate determining steps for dehydrogenation and cracking. The reaction orders for cracking and dehydrogenation were unity for all hydrocarbons studied.

\section{The Conversion of $\mathrm{B}$ ranched $\mathrm{H}$ ydrocarbons}

A detailed comparison between linear and the branched hydrocarbons was already given earlier (2). The conversion of i-butane on $\mathrm{H}$-ZSM 5 yielded methane, propene, and the butene isomers as primary products. A comparison of the selectivities of cracking and dehydrogenation for $n$-butane and i-butane is depicted in Fig. 1. The selectivity to dehydrogenation was higher for $\mathrm{i}$-butane than for $\mathrm{n}$-butane.

The product selectivities for the conversion of i-pentane and $\mathrm{n}$-pentane at $773 \mathrm{~K}$ are added in Fig. 1. Methane

\section{TABLE 3}

\section{A pparent Energies of Activation [kJ / $/ \mathrm{mol}]$ for C racking and Dehydrogenation of Propane to $n$-Pentane ( $n$-H exane)}

\begin{tabular}{lccccc}
\hline & \multicolumn{2}{c}{ HY-M } & & \multicolumn{2}{c}{ H-ZSM 5 } \\
\cline { 2 - 3 } \cline { 5 - 6 }$E_{A}$ & Cracking & D ehydrogenation & & Cracking & D ehydrogenation \\
\hline Propane & 165 & 65 & & 155 & 95 \\
n-Butane & 140 & 140 & & 135 & 115 \\
n-Pentane & 135 & 150 & & 120 & 150 \\
n-H exane & n.d. & n.d. & & 105 & 160 \\
\hline
\end{tabular}


Selectivity [mol\%]

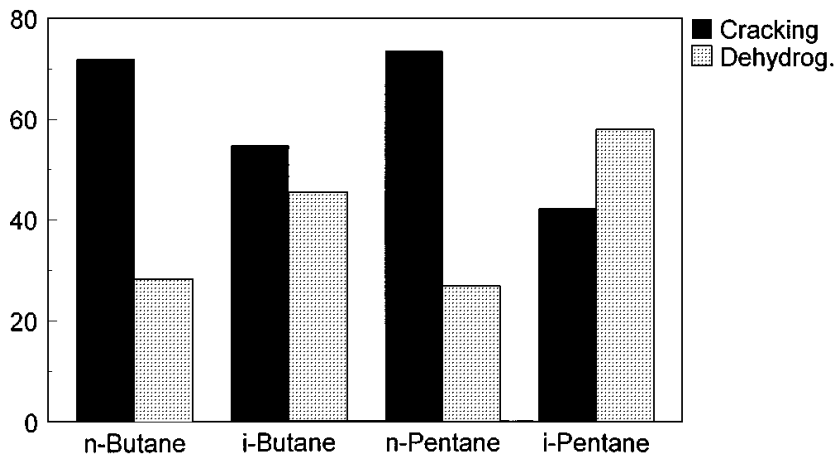

FIG. 1. Selectivities to cracking and dehydrogenation for $n$-butane, i-butane, n-pentane, and i-pentane on $\mathrm{H}$-ZSM 5 at $773 \mathrm{~K}$.

and butenes, ethane and propene, propane and ethane, and pentenes were the primary products in the conversion of $n$-pentane. The conversion of i-pentane yielded the same primary products as n-pentane with the exception of propane.

A s observed for the conversion of the butanes, the selectivity to dehydrogenation was higher for $\mathrm{i}$ - than for n-pentane.

Tables 4 and 5 reflect the rates of reaction and the energies of activation for the monomolecular cracking and dehydrogenation processes. The energies of activation for $\mathrm{n}$-butane and i-butane show a similar trend. The $\mathrm{E}_{\mathrm{A}}$ for dehydrogenation was somewhat smaller than the value for cracking. In contrast, the comparison of the energies of activation for $n$ - and i-pentane showed a distinctly different behavior. W ith i-pentane the energy of activation for cracking was much higher than that for n-pentane, while the energy of activation for dehydrogenation was the same for both hydrocarbons. These data suggest a change in the rate determining steps of both processes. L ooking closer to the energies of activation for cracking and breaking down the overall value to $E_{A} M$ ethane and $E_{A} E_{\text {thane, a clear distinction }}$ can be made between the two cracking processes, i.e., (i) the

\section{TABLE 4}

Conversion of $n$ - and $i$-Butane on H-ZSM5 at $773 \mathrm{~K}$; Rates of Product Formation $\times 10^{9}[\mathrm{~mol} / \mathrm{g} \mathrm{s} \mathrm{mbar}] ; \mathrm{E}_{A}[\mathrm{~kJ} / \mathrm{mol}]$

\begin{tabular}{lccc}
\hline \multicolumn{1}{c}{ R. no. } & Reaction & n-Butane & i-Butane \\
\hline $\mathrm{C}_{4}-1$ & $\mathrm{C}_{4} \mathrm{H}_{10} \rightarrow \mathrm{C}_{1}+\mathrm{C}_{\overline{3}}$ & 3.7 & 4.5 \\
$\mathrm{C}_{4}-2$ & $\mathrm{C}_{4} \mathrm{H}_{10} \rightarrow \mathrm{C}_{2}+\mathrm{C}_{\overline{2}}$ & 3.6 & 0 \\
$\mathrm{C}_{4}-3$ & $\mathrm{C}_{4} \mathrm{H}_{10} \rightarrow \mathrm{H}_{2}+\mathrm{C}_{4}$ & 2.7 & 4.0 \\
$\mathrm{C}_{4}-4$ & $\mathrm{C}_{4} \rightarrow 2 \mathrm{C}_{\overline{2}}$ & 0.1 & 0.1 \\
$\mathrm{r}_{\text {Cracking }}$ & & 7.3 & 4.5 \\
$\mathrm{r}_{\text {Dehydrog. }}$ & & 2.8 & 4.1 \\
$\mathrm{E}_{\text {A Cracking }}$ & & 135 & 125 \\
$\mathrm{E}_{\text {A Dehydrog. }}$ & & 115 & 100 \\
\hline
\end{tabular}

TABLE 5

Conversion of $n$ - and $i$-Pentane on H-ZSM 5 at $773 \mathrm{~K}$; R ates of Product Formation $\times 10^{9}[\mathrm{~mol} / \mathrm{gs} \mathrm{mbar}] ; E_{A}[\mathrm{~kJ} / \mathrm{mol}]$

\begin{tabular}{lccc}
\hline \multicolumn{1}{c}{ R. no. } & Reaction & n-Pentane & i-Pentane \\
\hline $\mathrm{C}_{5}-1$ & $\mathrm{C}_{5} \mathrm{H}_{12} \rightarrow \mathrm{C}_{1}+\mathrm{C}_{\overline{4}}$ & 9.4 & 17 \\
$\mathrm{C}_{5}-2$ & $\mathrm{C}_{5} \mathrm{H}_{12} \rightarrow \mathrm{C}_{2}+\mathrm{C}_{3}$ & 21 & 6.6 \\
$\mathrm{C}_{5}-3$ & $\mathrm{C}_{5} \mathrm{H}_{12} \rightarrow \mathrm{C}_{3}+\mathrm{C}_{2}$ & 7.2 & 0 \\
$\mathrm{C}_{5}-4$ & $\mathrm{C}_{5} \mathrm{H}_{12} \rightarrow \mathrm{H}_{2}+\mathrm{C}_{5}$ & 12.2 & 21 \\
$\mathrm{C}_{5}-5$ & $\mathrm{C}_{5} \rightarrow \mathrm{C}_{2}+\mathrm{C}_{3}$ & 9 & 12.5 \\
$r_{\text {Cracking }}$ & & 37.6 & 23.6 \\
$r_{\text {D ehydrog. }}$ & & 12.2 & 21 \\
$\mathrm{E}_{\text {A Cracking }}$ & & 115 & 150 \\
$\mathrm{E}_{\text {A M ethane }}$ & & 115 & 155 \\
$\mathrm{E}_{\text {A E thane }}$ & & 115 & 130 \\
$\mathrm{E}_{\text {A D ehydrog. }}$ & & 150 & 150 \\
\hline
\end{tabular}

formation of methane and butenes and (ii) the formation of ethane and propenes, denoted as $\mathrm{C}_{5}-1$ and $\mathrm{C}_{5}-2$ in Table 5 . Note that in the conversion of i-pentane the step producing butenes showed an apparent energy of activation which was $25 \mathrm{~kJ} / \mathrm{mol}$ higher than the step producing propenes, suggesting that the rate determining step for $C_{5}-1$ is the desorption of the olefins while for $\mathrm{C}_{5}-2$ it should still be protolysis of the $\mathrm{C}-\mathrm{C}$ bond.

\section{H/D ISOTOPE EFFECTS}

Figure 2 shows the rates of cracking and dehydrogenation as a function of the response time for an $n-(H / D)$ butane transient experiment (for a detailed interpretation see $\mathrm{R}$ ef. (38)). The rate of $\mathrm{n}-\left(\mathrm{H}_{10}\right)$ butane cracking was 1.7 times higher than that of $n-\left(D_{10}\right)$ butane indicating an appreciable isotope effect. N ote that the rate of cracking decreased in parallel to the decreasing proton concentration on the catalyst surface, indicating that the $\mathrm{O}-\mathrm{H}(\mathrm{O}-\mathrm{D})$ bond cleavage,

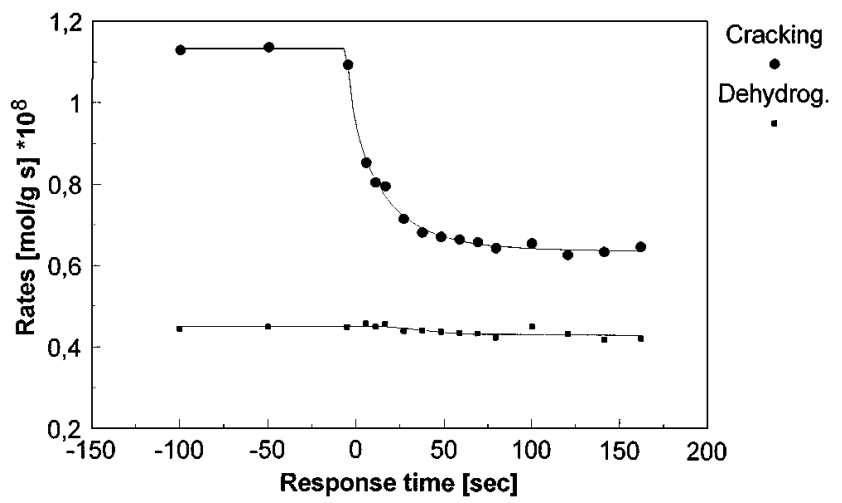

FIG. 2. Rates of cracking and dehydrogenation as a function of response time upon a steady state isotope transient ( $n-\mathrm{H}_{10}$-butane $\rightarrow n-D_{10}$ butane at $\mathrm{t}=0 \mathrm{~s}$; $\mathrm{H}-\mathrm{ZSM}-5, \mathrm{p}_{\mathrm{B} \text { utane }}=4 \mathrm{kPa} ; 773 \mathrm{~K}$ ). 
i.e., the protonation of the alkane (deprotonation of the zeolite) is most important for the rate determining step.

The results were confirmed by a step-up transient experiment (i.e., increasing the partial pressure of $n-\left(\mathrm{H}_{10}\right)$ butane from 0 to 40 mbar) using a catalyst, which only contained OD groups. The initial rate of cracking (surface covered with $\mathrm{D}$, feed $\mathrm{n}-\left(\mathrm{H}_{10}\right)$ butane) was again 1.7 times lower than the rate obtained after the surface deuterium atoms were fully exchanged with the protons from the molecules.

$B$ ecause the ratios of the rates were found to be identical for the reactions, i.e.,

$$
\frac{r\left(\mathrm{C}_{4} \mathrm{H}_{10}+\mathrm{H}^{*}\right)}{r\left(\mathrm{C}_{4} \mathrm{D}_{10}+\mathrm{D}^{*}\right)}=1.7=\frac{r\left(\mathrm{C}_{4} \mathrm{H}_{10}+\mathrm{H}^{*}\right)}{r\left(\mathrm{C}_{4} \mathrm{H}_{10}+\mathrm{D}^{*}\right)},
$$

we conclude that it is primarily the cleavage of the $\mathrm{OH}$ bond of the zeolite or the proton addition (i.e., a kinetic isotope effect) which is responsible for the difference in the rates.

In contrast to cracking, isotopic labeling of the feed or exchanging the surface protons with deuterium atoms hardly influenced the rate of dehydrogenation. Only a slightly lower rate was observed (factor 0.9-0.95) with n$\left(D_{10}\right)$ butane. This suggests that protonation of the feed is not part of the rate determining step in dehydrogenation. It is speculated that the rate determining step for dehydrogenation should be close to product desorption.

In order to facilitate the discussion, let us briefly summarize the major facts observed so far:

(i) The energies of activation for dehydrogenation increase with increasing molecular weight within a homologous row of paraffins. This is in clear contrast to the constant true energy of activation obtained for protolytic cracking indicating a change in the rate determining step of the reaction.

(ii) Comparing normal- and iso-paraffins, we observed a sudden increase in the energy of activation for cracking when the rate of olefin production exceeds a certain limit. $M$ uch more butenes are produced from i-pentane than from n-pentane; thus, olefin desorption becomes the slow step.

(iii) A distinct H/D isotope effect was observed for protolytic cracking, but not for dehydrogenation of n-butane indicating again that protonation of the alkane is not rate determining for dehydrogenation.

\section{Pressure Transient R esponse $E$ xperiments}

Pressure transient response experimentswere carried out with $\mathrm{n}$-butane in order to study the activity behavior for very short times on stream. Figure 3 shows the dependence of cracking and dehydrogenation as a function of time onstream at $803 \mathrm{~K}$ and a volumetric flow rate of $30 \mathrm{ml} / \mathrm{min}$; $32 \mathrm{mg}$ of $\mathrm{H}$-ZSM 5 were used without quartz dilution. The conversion at the final steady state was 3.5\% . For reasons of better comparison, the response curves of the products (i.e., concentration vs time) were normalized to their steady state

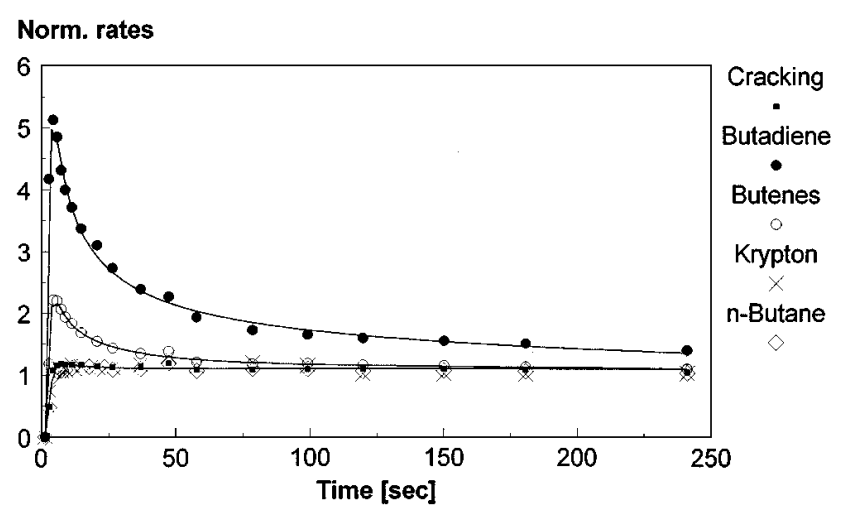

FIG. 3. Pressure transient response experiment. $n$-Butane (incr. $0 \rightarrow 4 \mathrm{kPa}$ ), $803 \mathrm{~K}, 32 \mathrm{mg} \mathrm{H}-Z \mathrm{SM} 5,30 \mathrm{ml} / \mathrm{min}$. R esponse functions of cracking and dehydrogenation products.

values. The steady state selectivities of cracking, primary and secondary dehydrogenation (formation of butenes and 1,3-butadiene) were $83.8,16$, and $0.2 \%$, respectively.

It can be seen that the reactant (n-butane) and the cracking products reach the steady state shortly after the response function of the tracer gas krypton and did not further depend on time on stream. The dehydrogenation response had a maximum at very short times on stream followed by a decrease to its final steady state value (the maximum rate at very short times on stream will be denoted as overshoot in the text.), which was reached after approximately 50 sin this experiment. This effect was even more pronounced for 1,3butadiene, i.e., the initial butadiene production exceeded the steady state rate by a factor of 5 , while the maximum value of the butene isomers was two times the steady state concentration. The response curve of 1,3-butadiene arrived at the steady state after $350 \mathrm{~s}$.

The dependence of the overshoot of the dehydrogenation products on changes in hydrodynamic residence time is shown in Fig. 4. When the residence time was increased

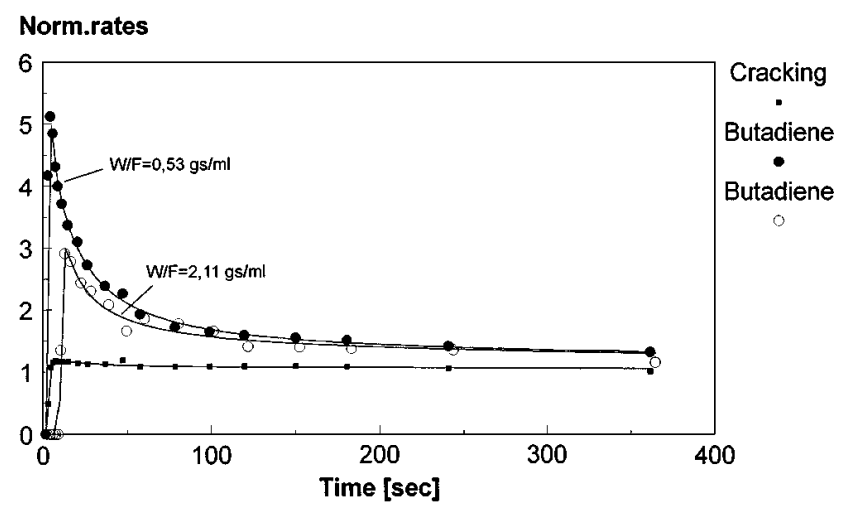

FIG . 4. D ependence of the transient response function as a function of residence time. Both step up transients: $n$-butane (incr. $0 \rightarrow 4 \mathrm{kPa}$ ), $803 \mathrm{~K}, 32 \mathrm{mg} \mathrm{H}-\mathrm{ZSM} 5,0.53 \mathrm{gs} / \mathrm{ml}$ (closed symbols), $2.11 \mathrm{gs} / \mathrm{ml}$ (open symbols), conversions: $3.5 \%, 14 \%$. 
from $0.53 \mathrm{~g} \mathrm{~s} / \mathrm{ml}$ to $2.11 \mathrm{~g} \mathrm{~s} / \mathrm{ml}$ by decreasing the volumetric flow rate from $60 \mathrm{ml} / \mathrm{min}$ to $15 \mathrm{ml} / \mathrm{min}$, using the same amount of catalyst, the intensities of the maxima of the response curves decreased. The change in residence time had no influence on the response curve of cracking. H owever, the initial slope of the response curves were shifted to higher times on stream with decreasing space velocity. $N$ ote again, that the transient response functions shown here were normalized to their steady state values, so that the increase in conversion from 3.5 to $14 \%$ after the decrease in space velocity is not seen.

$H$ ydrogen could not be monitored with the G C-M S-FID system. Thus, an online mass spectrometer wasused to monitor the hydrogen response on-line at the exit of the reactor. The results obtained for $\mathrm{H}-\mathrm{ZSM} 5$ are shown in Fig. 5. A fter increasing the n-butane pressure from 0 to $4 \mathrm{kPa}$ the hydrogen production immediately reached the steady state value, in clear contrast to the formation of the butenes. The reverse transient, i.e., switching from $n$-butane containing to pure helium, showed an immediate cease of hydrogen production, together with a sudden decrease in the concentrations of tracer gas and feed. Thus, the excess hydrogen produced from dehydrogenation during the overshoot must remain on the catalyst and it is supposed to desorb very slowly. A close inspection of the curve in Fig. 5 shows indeed that the concentration of hydrogen after the step down did not reach the baseline completely. This suggests that after a certain time (in the absence of the reaction) the surface should be free of hydrogen and the overshoot might be observed again. Therefore, the step up transient was repeated after a regeneration period of $5 \mathrm{~min}$ between the transients. $D$ uring this regeneration period the temperature was kept constant and $\mathrm{H}$ e was passed over the catalyst. The results of this transient response experiment are depicted in Fig. 6. It

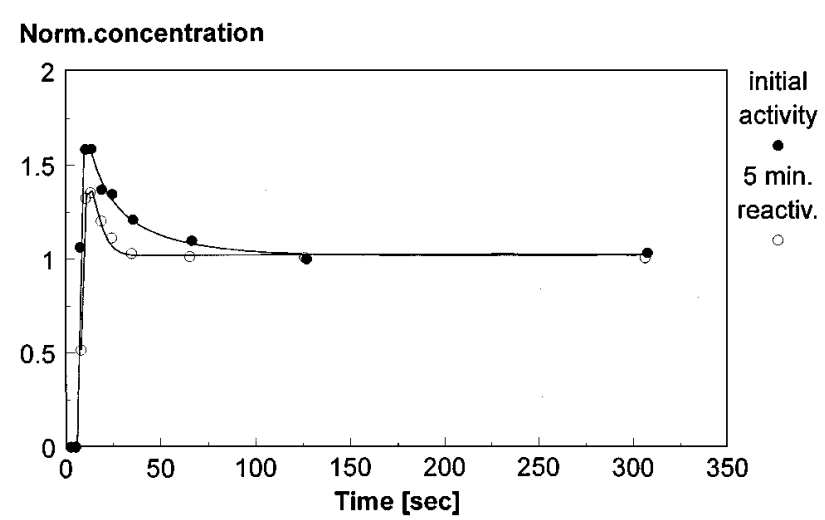

FIG. 6. Pressure transient response experiment. $\mathrm{n}-\mathrm{B}$ utane (incr. $0 \rightarrow 4 \rightarrow 0 \rightarrow 4 \rightarrow 0 \mathrm{kPa}$ ), $803 \mathrm{~K}, 32 \mathrm{mg} \mathrm{H}-\mathrm{ZSM} \mathrm{5,} 30 \mathrm{ml} / \mathrm{min}$. R esponse functions of dehydrogenation. R egeneration between the two step-up transients: $5 \mathrm{~min}$ in $\mathrm{H}$ e at reaction temperature.

can be clearly seen that 5 min were enough to free approximately $30 \%$ of the surface, as estimated from the integrated areas of the butenes during the overshoot. The initial rate of hydrogen desorption was estimated to be $10^{-8} \mathrm{~mol} / \mathrm{g} \mathrm{s}$.

Besides $\mathrm{H}-\mathrm{ZSM} 5$, pressure transient response experiments were carried out with H Y -P and H Y-M . For both catalysts a high initial dehydrogenation activity was observed which ceased with time on stream (Fig. 7) and reached steady state. The major difference between the two samples lies in this initial activity to dehydrogenation. I t was far higher on the parent (HY-P) than on the modified (HY-M) sample. A Iso the decay of the dehydrogenation activity was significantly slower (approx. $30 \mathrm{~min}$ ) than the decay observed with HY-M (approx. $5 \mathrm{~min}$ ). This suggests that extra framework species play a major role in the dehydrogenation of light alkanes at short times on stream. For a detailed

\section{Norm.concentration}

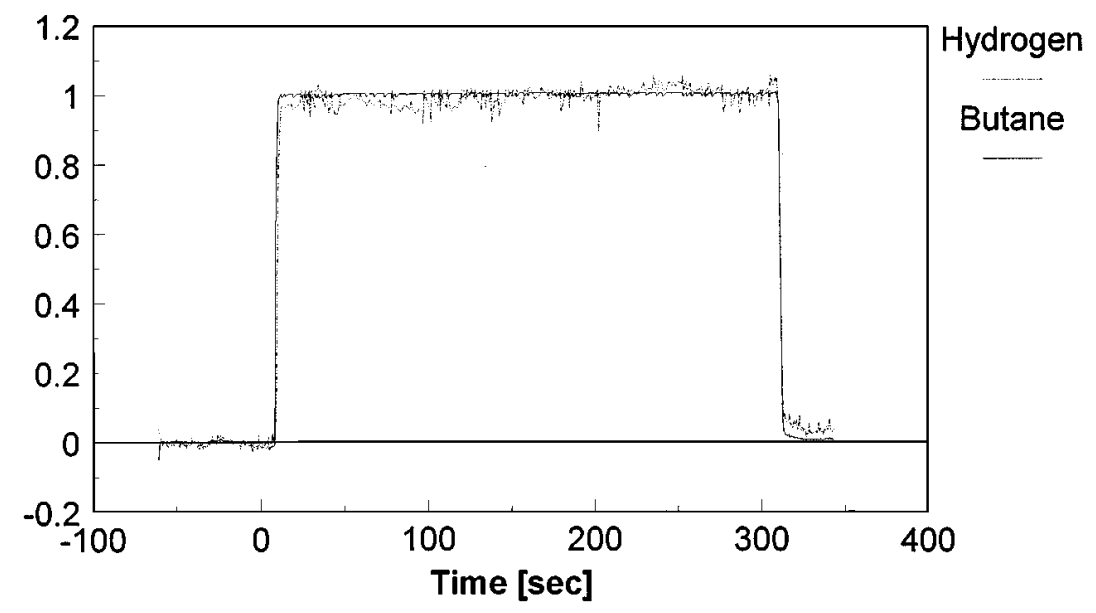

FIG. 5. Pressure transient response experiment. $\mathrm{n}$ - $\mathrm{B}$ utane $(0 \rightarrow 4 \rightarrow 0 \mathrm{kPa}), 803 \mathrm{~K}, 32 \mathrm{mg} \mathrm{H}-\mathrm{ZSM} 5,30 \mathrm{ml} / \mathrm{min}$. R esponse functions of $\mathrm{H}_{2}$ and n-butane. 
discussion of the results obtained with the faujasite samples see $R$ ef. (37).

Thus, $\mathrm{H}-\mathrm{ZSM} 5$ and $\mathrm{HY}-\mathrm{M}$ reached the steady state at short times on stream, while HY-P showed a distinctly different behavior. The initial activity to dehydrogenation was much higher and the decrease to a constant steady state value much longer compared to the other samples indicating a higher capability of storing hydrogen at the surface.

\section{C ofeeding $n-B$ utane and i-B utene}

In order to determine the influence of olefins on the rates and product selectivities of $n$-butane conversion, small amounts of $i$-butene were added to the $n$-butane feed. The quantities added to the feed stream were increased linearily as the conversion was increased, and were in the range of the amount produced via dehydrogenation of $n$-butane. The selectivities of the products are compiled in Fig. 8 for the cracking of $\mathrm{n}$-butane on $\mathrm{H}$-ZSM 5 at $803 \mathrm{~K}$ with and without addition of $\mathrm{i}$-butene to the feed, respectively. The selectivity to the butene isomersincreased from $15 \%$ to approximately $22 \%$ upon addition of $i$-butene to the feed. This level represents the amount of $i$-butene cofed.

I t wasobserved that the butene isomerswere always close to thermodynamic equilibrium $(1,2,18)$ suggesting that isomerization of the olefins is much faster than all other

\section{Conversion [mol\%]}
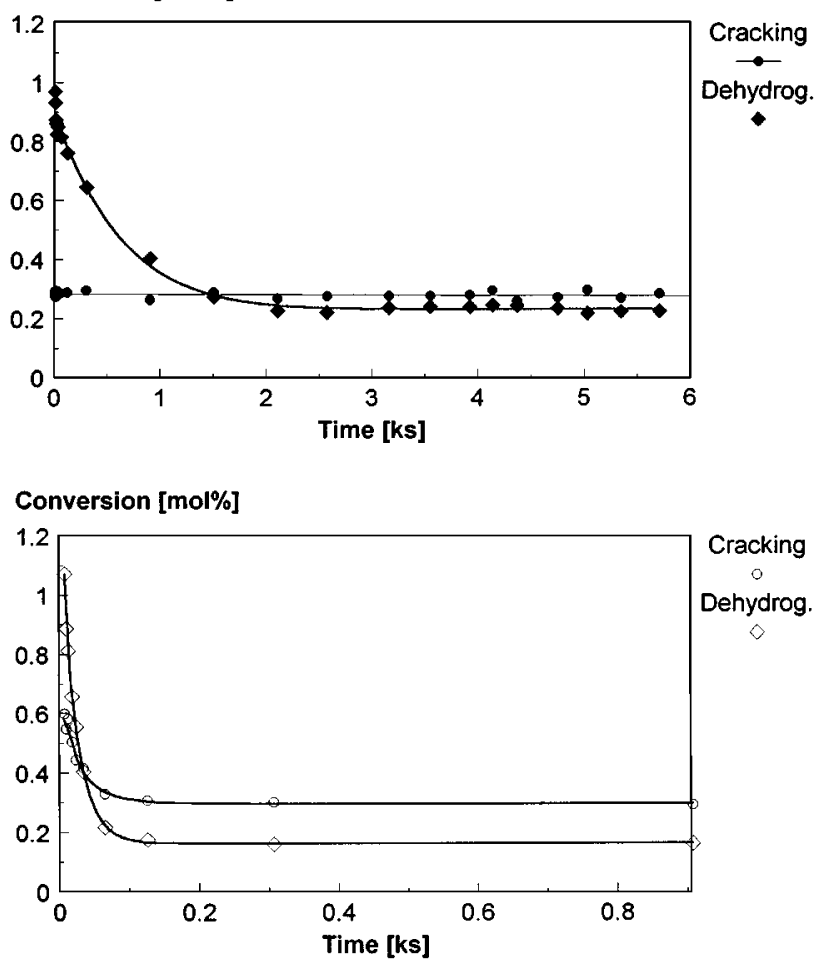

FIG. 7. Pressure transient response experiment of $n$-butane on $\mathrm{HY}-\mathrm{P}$ and $\mathrm{HY}-\mathrm{M}$ at $773 \mathrm{~K}$ (inc. $\mathrm{p}_{\mathrm{B} \text { utane }} 0 \rightarrow 4 \mathrm{kPa}$ ). Closed and open symbols refer to the parent and the modified faujasite, respectively.

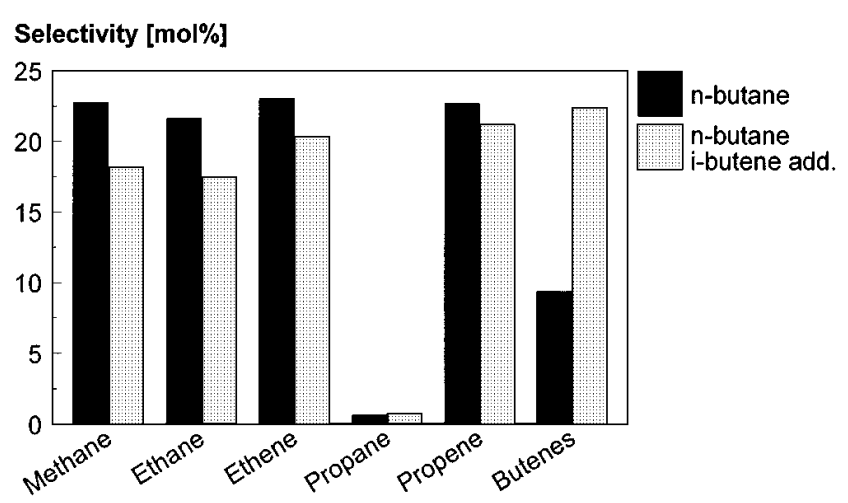

FIG. 8. The influence of the addition of i-butene upon conversion of n-butane at $803 \mathrm{~K}$.

surface processes involved in olefin (trans-)formation. The equilibrium selectivities were maintained during cofeeding of purei-butene indicating that isomerization of the butenes is fast compared to desorption.

A t higher conversion levels, the formation of butenes increased drastically. A this level of conversion, also the selectivity of the cracking products changed. The rate of production of ethene and propene was higher than that of methane and ethane, indicating secondary processes, e.g., the formation of an octene intermediate through dimerization followed by $\beta$-cracking. This behavior suggests a critical lower limit in the gas phase concentration of the butenes before secondary reactions set in, i.e., we infer that a certain butene concentration is required to start di- or oligomerization reactions. This interpretation would further suggest that the isomerization of butenes is a monomolecular process at low concentrations and does not require the formation of di- or oligomerization, while at high concentrations di- and oligomerization sets in.

\section{${ }^{13}$ C-TRACING STUDIES}

Theoretically, methane and propene as well as ethane and ethene contain one ${ }^{13} \mathrm{C}$-atom each, if cracking of $1,4-{ }^{13} \mathrm{C}_{2^{-}}$ n-butane exclusively proceed through protolysis. This leads to overall ${ }^{13} \mathrm{C}$ selectivities of $100 \%$ (methane), $50 \%$ (ethane and ethene), and 33\% (propene), respectively. B utenes, resulting from protolytic dehydrogenation should contain two ${ }^{13} \mathrm{C}$ atoms each corresponding to a ${ }^{13} \mathrm{C}$ selectivity of $50 \%$. The rates of $1,4-{ }^{13} \mathrm{C}_{2}$-n-butane conversion on $\mathrm{H}$-ZSM 5 between 733 and $823 \mathrm{~K}$ exactly equaled the conversion of ${ }^{12} \mathrm{C}_{4-}$ n-butane. Thus, an isotope effect or a preferential cleavage of a certain $\mathrm{C}-\mathrm{C}$ bond was not observed. The isotope selectivities

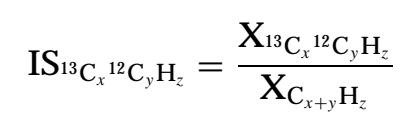

for the products and the reactant upon conversion of $\mathrm{n}-1,4-{ }^{13} \mathrm{C}_{2}$-butane on $\mathrm{H}$-Z SM 5 at $803 \mathrm{~K}$ are shown in Figs. 9 
Isotope selectivity [molfraction]

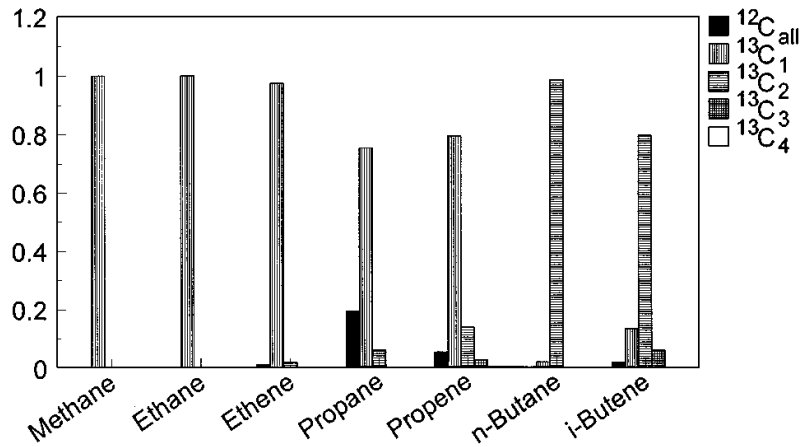

FIG . 9. Conversion of $\mathrm{n}-1,4-{ }^{13} \mathrm{C}$-butane on $\mathrm{H}$-ZSM 5 at $803 \mathrm{~K}$. I sotope selectivities of products and reactant; $5 \%$ overall conversion.

and 10. A t $803 \mathrm{~K}$ and a conversion of $5 \%$ hardly any carbon scrambling was detected in the products. M ethane and ethane contained exactly 100 and $50 \%{ }^{13} \mathrm{C}$, respectively. $E$ thene, propene, and the butene isomers showed small deviations from the ${ }^{13} \mathrm{C}$ distribution expected from pure monomolecular cracking. The extent of carbon scrambling, however, increased with the increasing carbon chain length of the olefins. These results clearly demonstrate the increased reactivity of the olefins with the catalyst surface (see also (38)). Figures 11-13 show the influence of conversion and temperature on the extent of carbon scrambling. W ith decreasing temperature and increasing conversion the extent of carbon scrambling in the olefins increases. This is explained with an increased surface concentration of these products and hence an increased contribution of bimolecular reactions. N ote that the ${ }^{13} \mathrm{C}$ distributions in methane, ethane, and n-butane did not deviate from those expected for protolytic cracking. This suggests that once methane and ethane are formed, they do not undergo any further reactions and desorb immediately.

The ${ }^{13} \mathrm{C}$ isotope selectivities for reactants and products upon cofeeding $n-{ }^{12} C_{4}$-butane and $n-1,4-{ }^{13} C_{2}$-butane are

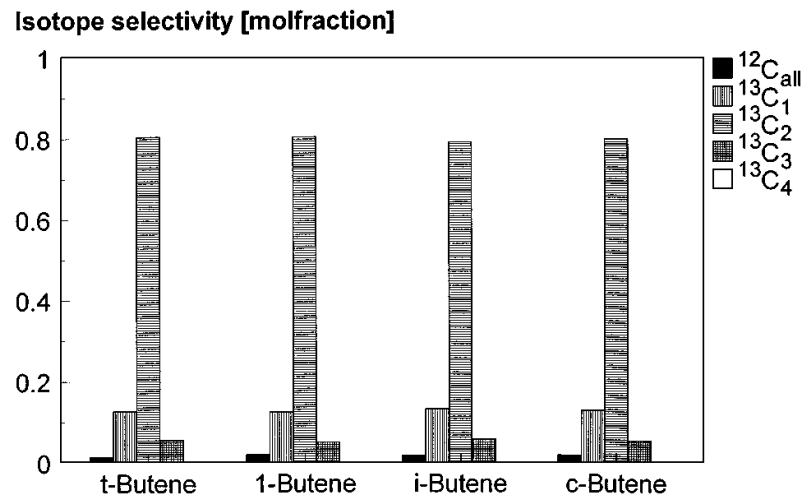

FIG. 10. Conversion of $\mathrm{n}-1,4-{ }^{13} \mathrm{C}$-butane on $\mathrm{H}-\mathrm{ZSM} 5$ at $803 \mathrm{~K}$. I sotope selectivities of butene isomers; $5 \%$ overall conversion.
Isotope selectivity [molfraction]

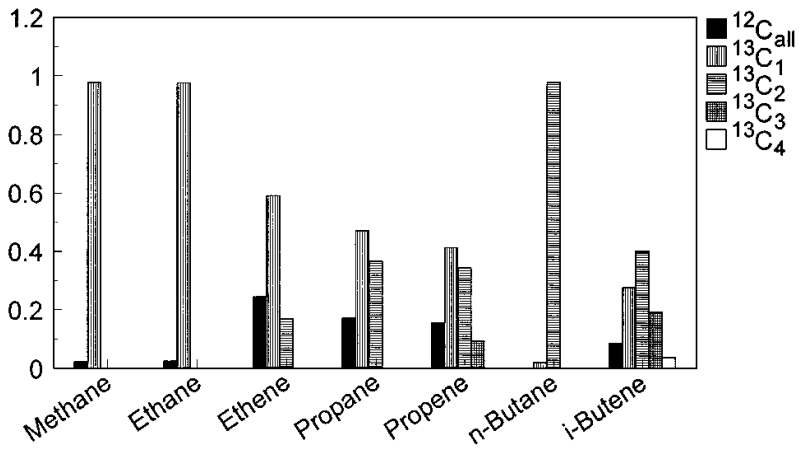

FIG . 11. Conversion of $\mathrm{n}-1,4-{ }^{13} \mathrm{C}$-butane on $\mathrm{H}-\mathrm{ZSM} 5$ at $803 \mathrm{~K}$. I sotope selectivities of products and reactant; $50 \%$ overall conversion.

depicted in Fig. 14. It might be clearly understood from these results that carbon scrambling does not occur under the reaction conditions applied. N ote that, nevertheless, the butenes were found to match their thermodynamic equilibrium distribution, suggesting, that isomerization occurs via a monomolecular process under the differential operating conditions employed.

\section{DISCUSSION}

\section{The $R$ ate $D$ etermining Step}

The experiments carried out so far clearly indicate that the rate determining steps of cracking and dehydrogenation are different. A first indication was given from the apparent energies of activation for the conversion of normal alkanes. In contrast to the $\mathrm{C}-\mathrm{C}$ bond cleavage, where a constant true energy of activation was observed, dehydrogenation of the alkanes showed an increase in the energies of activation. N ote that the interaction of higher olefins with an acid catalyst surface is stronger than that of smaller alkenes. Thus, if desorption were rate determining, a trend similar to the described would be expected.

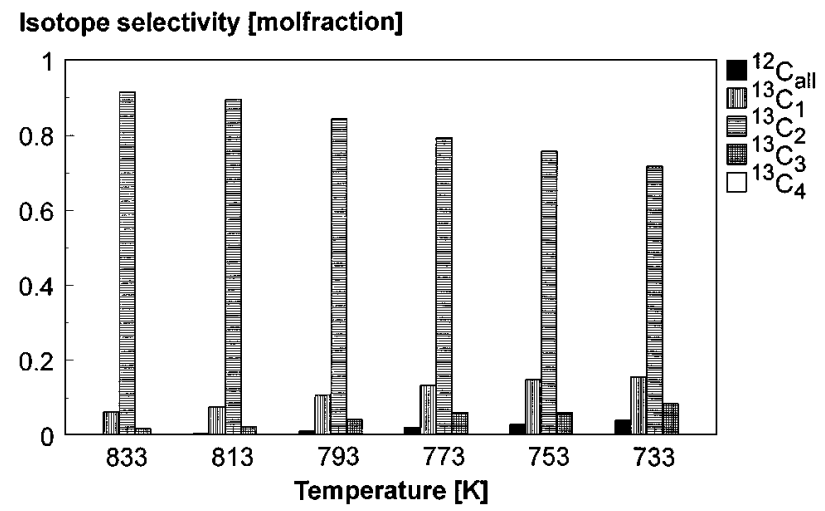

FIG . 12. Conversion of $n-1,4-{ }^{13} \mathrm{C}$-butane on $\mathrm{H}$-ZSM 5. I sotope selectivities of butene isomers as a function of temperature. 


\section{Isotope selectivity [molfraction]}

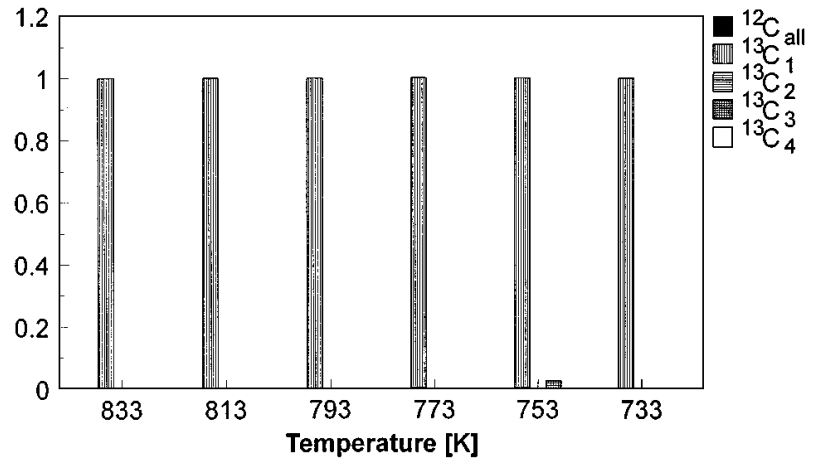

FIG . 13. Conversion of $n-1,4-{ }^{13} \mathrm{C}$-butane on $\mathrm{H}$-ZSM 5. I sotope selectivities of ethane as a function of temperature.

A second argument for different rate limiting steps of cracking and dehydrogenation can be drawn from the comparison of the energies of activation observed for linear and branched paraffins. The conversion of i-pentane yields mainly methane and butene isomers as primary cracking products, while $\mathrm{C}_{2^{-}}$and $\mathrm{C}_{3^{-}}$paraffins and olefins are the main products from $n$-pentane cracking. Thus, it appears from the comparison of the energies of activation that the rate constant of $\mathrm{C}_{4-}$ production becomes higher than the rate constant of olefin desorption in the case of i-pentane and the energy of activation for the production of methane (and butenes) does no longer reflect the process of protolysis.

The third argument for the difference in the rate determining steps arises from the presence/absence of an isotope effect in $\mathrm{n}-(\mathrm{H} / \mathrm{D})$ butane conversion. While a large isotope effect was observed for cracking, a change in the rates has not been detected when replacing butane $(\mathrm{H})$ with deuterated butane.

Thus, we believe that protolysis limits the rate of cracking while olefin desorption controls the rate of dehydrogenation. However, ${ }^{13} \mathrm{C}$ and $\mathrm{H} / \mathrm{D}$ tracer experiments suggest that the rates of dehydrogenation and desorption must

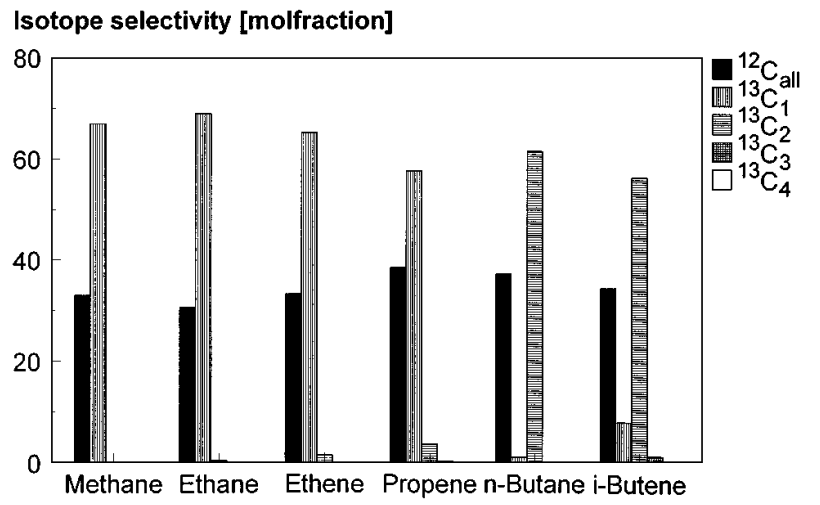

FIG. 14. Conversion of $n-1,4-{ }^{13} \mathrm{C}$-butane and $\mathrm{n}-{ }^{12} \mathrm{C}$-butane on $\mathrm{H}$ ZSM 5 at $803 \mathrm{~K}$. I sotope selectivities of reactant and products. be in the same order of magnitude. If all reactions preceding the rate determining step are fast, compared to the latter, quasi-equilibrium is established for these reactions. This requires that re-hydrogenation (of butenes) occurs nearly as fast as dehydrogenation (of butane). Co-feeding $n-\left(H_{10}\right)$ butane and $n-\left(D_{10}\right)$ butane $(38)$, however, showed that the deuterium distribution in butane was far different from that in the butenes suggesting that dehydrogenation/ hydrogenation equilibrium was not established. M oreover, an appreciable extent of ${ }^{13} \mathrm{C}$ scrambling would be expected in $n$-butane at high conversions of $n-1,4-{ }^{13} \mathrm{C}$-butane, because a high extent of ${ }^{13} \mathrm{C}$ scrambling was observed in the butenes at these conversions. B ecause none of these conditions were observed, it must be concluded that the rates of dehydrogenation and desorption are similar.

A Ithough protolysis was concluded to represent the slow step in cracking of $n$-alkanes, it strongly depends on the rate of olefin formation via cracking whether protonation of the feed or desorption of the olefins limits the overall process for iso-paraffins.

\section{A Second D ehydrogenation Pathway}

The transient response studies suggest two regimes for dehydrogenation of alkanes, (i) a high initial activity to dehydrogenation at short times on stream, and (ii) a much lower steady state activity to dehydrogenation. In contrast, cracking reached the steady state following the tracer gas and did not further depend on time on stream. It was shown earlier that protolytic cracking exclusively proceeds on B rønsted acid sites (1,2). B ecause the cracking activity did not change with time on stream, deactivation of these sites can be excluded to occur. I t might, thus be speculated that dehydrogenation, proceeds additionally at a second site. This pathway must, thus, be blocked after short times on stream.

The decrease of the high initial dehydrogenation activity was much slower on the parent faujasite, than on all other materials (HY-M , H-ZSM 5). Because this material contained a large amount of extra framework aluminum, we speculate that these moieties are involved in the active sites for the second dehydrogenation pathway.

From these results it appears that blocking of the second pathway, which is only active for dehydrogenation, causes the steep decrease in dehydrogenation activity after short times on stream. O n-line monitoring of hydrogen after a pressure step up transient, however, showed that hydrogen reached the steady state value, together with the cracking products and the tracer gas. Thus, at short times on-stream less hydrogen than olefins desorb from the catalyst surface, indicating that hydrogen is trapped on the catalyst. The "step-down" transient response experiment, followed by a repetition of the "step-up" transient showed that the blocking is reversible and that these sites are freed slowly by desorbing hydrogen. 
Based on the reports of Iglesia, Boudart, and Temkin (39-42) we propose the following model to explain this behavior. The initial dehydrogenation rate (on the additional site, not on the B rønsted acid sites) is high. D ehydrogenation proceeds by stepwise removal of hydrogen atoms, in contrast to protolytic dehydrogenation on Brønsted acid sites. We speculate that hydrogen adatoms are stored on the surface and their recombinative desorption is slow. Thus, as the reaction proceeds, the surface is subsequently filled with hydrogen species. This ensemble of hydrogen species at the catalyst surface was denoted as hydrogen pool and it corresponds to high hydrogen surface fugacities (virtual pressures). Because the recombinative desorption of hydrogen is rate determining, all preceding steps must be in quasi equilibrium. This implies a zero order with respect to the reactant at steady state for the second pathway.

B ecause the gas phase concentration of desorbing hydrogen immediately reached steady state, this reaction mechanism only explains a part of the catalytic activity for dehydrogenation, i.e. the contribution of the second active site. If the overall formation of olefins was limited by hydrogen desorption, a gentle initial slope of the appearance of hydrogen in the gas phase should have been observed.

The dependence of the observed overshoot on the hydrodynamic residence time, i.e., a lower maximum concentration of the butenes at higher values of hydrodynamic residence time $(\tau)$ relative to steady state, can be explained by our model with respect to the behavior of a differential plug flow reactor. U sing K obayashi's transient response data (Kobayashi (43) reported an overshoot behavior of the $\mathrm{N}_{2}$ response for the decomposition of $\mathrm{N}_{2} \mathrm{O}$ on $\mathrm{MnO}_{2}$ and explained it by the rate limiting desorption of oxygen from the surface) for the decomposition of $\mathrm{N}_{2} \mathrm{O}$ on $\mathrm{M} \mathrm{nO}_{2}$, B ennett (44) discussed the possible types of overshoot behavior with a variation in hydrodynamic residence time $(\tau)$. It was demonstrated that for high residence times the overshoot could not be observed, while at very low residence times the overshoot peak becomes a cusp. This model of Kobayashi is in good qualitative agreement with our experimental results, if we assume, that hydrogen disposal is the rate determining step of the second dehydrogenation pathway.

Thus, it is concluded that dehydrogenation proceeds via two routes, i.e., (i) protolytic dehydrogenation on B rønsted acid sites (reaches immediately the steady state, together with cracking) and (ii) dehydrogenation on a different kind of sites (possibly species affiliated to extra framework aluminum).

A t steady state, the orders of dehydrogenation were determined to be unity with respect to the reactant for all hydrocarbons studied. This indicates that the additional dehydrogenation mechanism does not contribute significantly at steady state. If it contributed, we would expect a lower overall reaction order, because the hydrogen desorption controlled pathway would be zero order with respect to the reactant.

\section{I somerization}

The concentrations of the butene- and the penteneisomers were found to be in thermodynamic equilibrium, independent whether they were formed via cracking or via dehydrogenation. This indicates that isomerization (double bond-, cis/trans-, and skeletal-) is faster than desorption.

Two mechanisms of olefin isomerization were proposed in literature, i.e., an intra- and an intermolecular rearrangement. The monomolecular pathway was often rejected (especially for the butenes) on the basis of the argument that rearrangement of the butenes would require the formation of a primary carbenium ion to form a cyclopropylintermediate, which is not very likely to occur. The ${ }^{12} \mathrm{C} /{ }^{13} \mathrm{C}$ cofeeding experiment clearly showed that carbon scrambling occurred to a minor extent in the butenes. It was, therefore, concluded that isomerization must occur via a monomolecular rearrangement under differential operating conditions. A t high levels of conversion and lower temperatures (both factors increase the surface coverage); i.e., under conditions where bimolecular cracking prevails, the extent of carbon scrambling also increased. Thus, we propose that under these conditions oligomer (dimer) formation followed by $\beta$-cracking is the preferred pathway in olefin isomerization.

\section{CONCLUSIONS}

Steady state-, transient response-, and isotope-tracing studies revealed two mechanisms of dehydrogenation. The main pathway is represented by monomolecular, protolytic dehydrogenation. This reaction contributes most to steady state olefin production. The rate determining step for this pathway is represented by olefin desorption from the catalyst surface. A dditionally, at initial stages of the reaction, extraframework aluminum moieties are concluded to play a significant role for dehydrogenation. U nder those conditions, dehydrogenation in this second reaction pathway proceeds via stepwise hydrogen removal. The hydrogen species recombine and desorb very slowly and quench, thus, the rate of this process at steady state ( product = hydrogen inhibition). Depending on the process conditions, olefins undergo secondary cracking, oligomerization, or isomerization. The latter proceeds via intramolecular rearrangement at low conversions, possibly via a cyclopropylcarbenium ion. A treaction conditions where bimolecular cracking prevails, isomerization is concluded to occur via secondary cracking of di- or oligomers.

\section{ACKNOWLEDGMENT}

Financial support by the Christian D oppler Laboratories for $\mathrm{H}$ eterogeneous $C$ atalysis is gratefully acknowledged. 


\section{REFERENCES}

1. Narbeshuber, T. F., Vinek, H., and Lercher, J. A ., J. Catal. 157, 388 (1995).

2. Narbeshuber, T. F., Ph.D. thesis, U niversity of Twente, E nschede, NL, 1994.

3. Haag, W. O., and D essau, R. M., in "Proceedings 8th International Congress on Catalysis, B erlin, 1984," Vol. II, p. 305, D echema, Frankfurt am Main.

4. K rannila, H., H aag, W. O., and G ates, B. C., J. Catal. 135, 115 (1992).

5. Lercher, J., van Santen, R. A ., and Vinek, H., Catal. L ett. 27, 91 (1994).

6. B andiera, J., and Taarit, Y. B., A ppl. Catal. 76, 199 (1991).

7. Brenner, A ., and E mmett, P. H., J. Catal. 75, 410 (1982).

8. M cVicker, G. B., K ramer, G. M., and Ziemiak, J. J., J. Catal. 83, 286 (1983).

9. K ramer, G. M ., and M cVicker, G. B., J. Catal. 115, 608 (1989).

10. H all, W. K., Lombardo, E. A ., and Engelhardt, J., J. Catal. 115, 611 (1989).

11. Bizreh, Y. W., and G ates, B. C., J. Catal. 88, 240 (1984).

12. M arczewski, M., J. Chem. Soc. Faraday Trans. I 82, 1687 (1986).

13. A bbot, J., and Wojciechowski, B. W., J. Catal. 113, 353 (1988).

14. G ianetto, G., Sansare, S., and G uisnet, M ., J. Chem. Soc. Chem. Commun., 1302 (1986).

15. B eyer, H . K ., H orvath, J., and R eti, F., R eact. K inet. Catal. L ett. 14, 395 (1980).

16. L ombardo, E . A ., and H all, K. W., J. Catal. 112, 565 (1988).

17. A bbot, J., and Woiciechowski, B. W., J. Catal. 107, 451 (1987).

18. A bbot, J., and Wojciechowski, B. W., Can. J. Chem. Eng. 63, 818 (1985).

19. Ko, A. N., and Wojciechowski, B. W., Int. J. Chem. K in. 15, 1249 (1983).

20. A bbot, J., and Wojchiechowski, B. W., J. Catal. 90, 270 (1984).

21. West, P. B., H aller, G. L., and B urwell, R . L., J. Catal. 29, 486 (1973).

22. Gerberich, H. R., and H all, W. K., J. Catal. 5, 99 (1966).
23. L ucchesi, P. J., B aeder, D. L., and Longwell, P. J., J. A m. Chem. Soc. 81, 3235 (1959).

24. Jacobs, P. A ., D eclerk, L. J., Vandamme, L . J., and U ytterhoeven, J. B., J. Chem. Soc., Faraday Trans. 71(7), 1545 (1975).

25. Cross, N. E., K emball, C., and Leach, H. F., A dv. Chem. Ser. 102, 389 (1971).

26. H ightower, J. W., and H all, W. K., J. Phys. Chem. 71, 1014 (1964).

27. Hightower, J. W., Gerberich, H. R., and Hall, W. K., J. Catal. 7, 57 (1967).

28. H ightower, J. W., and H all, W. K., A mer. Inst. Chem. E ng. Symp. Ser. 63, 122 (1967).

29. G oldwasser, J., E ngelhardt, J., and H all, W. K., J. C atal. 71, 381 (1981).

30. G oldwasser, J., E ngelhardt, J., and H all, W. K., J. Catal. 70, 275 (1981).

31. Brouwer, D. M., and Hogeveen, H., Prog. Phys. Org. Chem. 9, 179 (1972).

32. H oužvička, J., and Ponec, V., Ind. Eng. Chem. Res. 36, 1424 (1997).

33. M axwell, I., and N aber, J. E ., Catal. L ett. 12, 105 (1992).

34. M ooiweer, H. H., de Jong, K. P., K raushaar-C zarnetzki, B., Stork, W. H. J., and Krutzen, B. C. H., Stud. Surf. Sci. Catal. 84(C), 2327 (1994).

35. O'Y oung, C., X u, W., Simon, M., and Suib, S., Stud. Surf. Sci. Catal. 84(C), 1671 (1994).

36. Stockenhuber, M., Ph.D. thesis, Technical U niversity of Vienna, Vienna, A ustria, 1994.

37. N arbeshuber, T. F., B rait, A., Seshan, K., and Lercher, J. A ., A ppl. Catal. A : G eneral 146, 119 (1996).

38. Narbeshuber, T. F., Stockenhuber, M., Brait, A., Seshan, K., and Lercher, J. A ., J. Catal. 160, 183 (1996).

39. Temkin, M. I., and Pyzhev, V., A cta Physicochim. 12, 327 (1940).

40. B oudart, M., J. P hys. Chem. 87, 2786 (1983).

41. B oudart, M., Ind. Eng. Chem. Fund. 25, 70 (1986).

42. I glesia, E ., B aumgartner, J. E ., and Price, G. L ., J . Catal. 134, 549 (1992).

43. Kobayashi, M., and Kobayashi, H ., J. Chem. E ng. J pn. 6(5), 438 (1973).

44. Bennett, C. O., Catal. R ev. Sci. Eng. 13(2), 121 (1976). 